\title{
Effect of the Combination Hot Water - Calcium Chloride on the In Vitro Growth of Colletotrichum gloeosporioides and the Postharvest Quality of Infect- ed Papaya
}

\author{
Lidia Elena Ayón-Reyna ${ }^{1}$, José Ángel López-Valenzuela ${ }^{1}$, Francisco Delgado-Vargas ${ }^{1}$, Martha Edith López-López, \\ Francisco Javier Molina-Corral ${ }^{2}$, Armando Carrillo-López ${ }^{1}$, and Misael Odín Vega-García ${ }^{1 *}$ \\ ${ }^{I}$ Facultad de Ciencias Químico Biológicas, Universidad Autónoma de Sinaloa, Cd. Universitaria, Av. de las Américas y \\ Josefa Ortiz S/N, Culiacán, Sinaloa, 80010, México \\ ${ }^{2}$ Centro de Investigación en Alimentación y Desarrollo, A.C. Av. Río Conchos $S / N$, Parque Industrial, Cd. Cuauhtémoc, \\ Chihuahua, 31570, México
}

(Received on January 9, 2017; Revised on July 13, 2017; Accepted on July 17, 2017)

Anthracnose of papaya fruit caused by the fungus Colletotrichum gloeosporioides is one of the most economically important postharvest diseases. Hot water immersion (HW) and calcium chloride (Ca) treatments have been used to control papaya postharvest diseases; however, the effect of the combination HW-Ca on the pathogen growth and the development of the disease in infected papaya fruit has been scarcely studied. The aim of this study was to evaluate the effect of the HWCa treatment on the in vitro growth of $C$. gloesporioides conidia and the quality of infected papaya. In vitro, the HW-Ca treated conidia showed reduced mycelial growth and germination. In vivo, the HW-Ca treatment of infected papaya delayed for 5 days the onset of the anthracnose symptoms and improved the papaya postharvest quality. The combined treatment HW-Ca was better than any of the individual treatments to inhibit the in vitro development of $C$. gloeosporioides and to reduce the negative effects of papaya anthracnose.

Keywords : anthracnose, calcium chloride, Carica papaya, hot water treatment, postharvest quality

\footnotetext{
*Corresponding author.

Phone) 52-6677136615 (ext. 111), FAX) 52-6677136615 (ext. 102)

E-mail)mvega6@yahoo.com

(c) This is an Open Access article distributed under the terms of the Creative Commons Attribution Non-Commercial License (http:// creativecommons.org/licenses/by-nc/4.0) which permits unrestricted noncommercial use, distribution, and reproduction in any medium, provided the original work is properly cited.
}

Articles can be freely viewed online at www.ppjonline.org.
Handling Associate Editor : Sang, Mee Kyung

Papaya (Carica papaya L.) is an important tropical fruit, which is appreciated for its high nutrient content and pharmacological benefits (Ong et al., 2013). The world trade of this fruit is increasing, gaining popularity in the local and export markets (Ali et al., 2015). However, papaya marketing is limited because of its very short shelf life associated with rapid weight loss, pulp softening, and susceptibility to postharvest diseases (Ayón-Reyna et al., 2015; Madani et al., 2014), which is the main concern of papaya growers (Ong et al., 2013).

Anthracnose is a postharvest disease caused by the fungus Colletotrichum gloeosporioides (Penz.) Penz. \& Sacc., one of the most devastating and economically significant pathogen that affects papaya fruit causing postharvest losses of about $40-100 \%$ in developing countries (Ademe et al., 2013; Machado et al., 2014; Madani et al., 2014). Papaya anthracnose initiates in the field when the developing fruit is infected, but the symptoms generally appear until the fruit ripens. Anthracnose in papaya is characterized by sunken areas and water soaked spots, which rapidly expand and the infected tissue becomes soft and then necrotic (Ajay Kumar, 2014).

Several chemical fungicides such as prochloraz, propiconazole, benomyl, and thiabendazole are commonly used to control anthracnose disease (Ali et al., 2015; Li et al., 2013; Perumal et al., 2016). However, the long-term use of fungicides has resulted in pathogen resistance to these chemicals (Ali et al., 2015). Moreover, epidemiological studies have shown that many of these pesticides are toxic 
to human beings. Over the past several decades, pesticides have been banned or otherwise regulated because of concerns related to their carcinogenic potential or other risks to human health or the environment (National Research Council, 1996). In this sense, consumers prefer the consumption of fruits that have not been treated with chemical products (Kechinski et al., 2012). Thus, non-chemical treatments are required to protect the papaya fruit of different diseases and to extend their shelf life.

Immersion of the fruit in hot water (HW) is an effective non-chemical treatment to kill or retard the development of pathogens. In addition, the HW treatment delays the ripening process, increases the shelf life, and preserves the fruit quality (Li et al., 2013; Martins and Blum, 2014). The advantages of HW treatment include its relatively easy application, short treatment time, and its effectiveness in killing pathogens that cause skin-borne diseases (Kechinski et al., 2012). Hot water treatment has shown to be effective in reducing the viability of various pathogens such as $C$. gloeosporioides in papaya and guava (Ferraz et al., 2013; Li et al., 2013), Monilinia laxa in peach (Spadoni et al., 2014), and Penicillium expansum in apple (Conway et al., 1999). A comparative study between hot air and the chemical fungicide thiabendazole showed that both treatments had the same effect on inoculum development of C. gloeosporioides in papaya (Pérez-Carrillo and Yahia, 2004).

Another method used to control fruit postharvest diseases is the application of calcium (Ca); fruits containing high concentration of calcium are less susceptible to fungal infections (Awang et al., 2011). Also, Ca treatment delays the ripening processes of several fruits and vegetables and increases their postharvest quality (Al-Eryani et al., 2008). Calcium interacts with pectin and helps to preserve the fruit firmness by maintaining the cell wall integrity, which reduces the fruit susceptibility to the attack of pathogens (Madani et al., 2016). In this regard, Ca treatment can control anthracnose disease in some fruits like papaya (Madani et al., 2016), apple (Zhao and Wang, 2015), and dragon fruit (Ghani et al., 2011).

Nowadays, research studies have focused on combined techniques with better antifungal efficiencies than the chemical alternatives (Kechinski et al., 2012). The combination of hot water and calcium (HW-Ca) treatments has been used to control postharvest diseases and has been shown to maintain the postharvest quality of the fruits, especially the firmness (Aguayo et al., 2008). HW-Ca was effective in reducing the severity of anthracnose caused by C. gloeosporioides in papaya (Ayón-Reyna et al., 2017) and mango (Dessalegn et al., 2013) and by Colletotrichum simmondsii in guava (Cruz et al., 2015), obtaining better results with the combination compared with the individual treatments. These HW-Ca treatments have also reduced the decay area and incidence of Penicillium expansum and Botrytis cinerea in apple fruit (Sharma et al., 2013). However, the effect of the HW-Ca treatment on papaya fruit diseases has been scarcely studied. We previously reported that HW-Ca treated papaya fruit are better protected against the C. gloeosporioides infection (Ayón-Reyna et al., 2017), but the in vitro effect of this treatment on $C$. gloeoporioides has not been reported. The aim of the present study was to evaluate the effect of hot water (HW), calcium (Ca), and HW-Ca treatments on the in vitro development of $C$. gloeosporioides and the postharvest quality of papaya fruit infected with this fungus.

\section{Materials and Methods}

Fungal pathogen isolation. The fungus Colletotrichum gloeosporioides was isolated from infected papaya fruit and identified by molecular analysis (Accession number - HM222960.1; Similarity 100\%). It was plated on potato dextrose agar (PDA, MCD LAB, Tlalnepantla, Edo. de Mexico, Mexico) and incubated at $28 \pm 2{ }^{\circ} \mathrm{C}$ to obtain material for further studies. The conidial suspension used for in vitro assays and fruit inoculations was prepared as described by Ayón-Reyna et al. (2017).

In vitro antifungal assay. Ten milliliters of conidial suspension $\left(1.5 \times 10^{6}\right.$ conidia $\left./ \mathrm{ml}\right)$ was centrifuged at 5000 $\times g$ for $20 \mathrm{~min}$ at room temperature (Eppendorf 5804-R, Hamburg, Germany). The pellet containing conidia was recovered, resuspended in $10 \mathrm{ml}$ of different media, and exposed for $20 \mathrm{~min}$ at different temperatures: (a) water at $25^{\circ} \mathrm{C}$ (control), (b) water at $48^{\circ} \mathrm{C}$ (HW treatment), (c) $1 \%$ calcium chloride solution at $25^{\circ} \mathrm{C}(\mathrm{Ca}$ treatment), and (d) $1 \%$ calcium chloride solution at $48^{\circ} \mathrm{C}$ ( $\mathrm{HW}-\mathrm{Ca}$ treatment). One microliter of each conidial suspension was poured into the center of a $90 \times 15 \mathrm{~mm}$ Petri dish containing PDA, incubated at $28^{\circ} \mathrm{C}$, and the radial mycelial growth for each treatment was measured when the mycelia of the control reached the edge of the plate. Results were expressed as percentage of inhibition using the formula described by Ong et al. (2013).

$$
\% \text { Inhibition }=\frac{\mathrm{Rc}-\mathrm{R}}{\mathrm{Rc}} \times 100
$$

where,

$\mathrm{Rc}=$ Radial growth in control

$\mathrm{R}=$ Radial growth in treatment

Conidial germination inhibition was evaluated accord- 
ing to Ali et al. (2015). Briefly, $100 \mu 1$ of each treated conidial suspension was pipetted onto PDA dish, spread with a sterile loop, and the dish was incubated at $28^{\circ} \mathrm{C}$ for $6 \mathrm{~h}$. The conidia germination was examined under a light microscope at $40 \times$ magnification (Axiophot photomicroscope Carl Zeiss, Germany). One hundred conidia were examined, and germination was established by the development of germ tubes. A conidium was considered germinated when its germ tube length equaled or exceeded half the length of the conidium. Results were expressed as percentage of germination inhibition according to the formula described by Ong et al. (2013).

$$
\% \text { Germination inhibition }=1-\left(\frac{\mathrm{G}}{\mathrm{Gc}}\right) \times 100
$$

where,

$G=$ Number of germinated spores in the treatment

$\mathrm{Gc}=$ Number of germinated spores in the control

Three replicates were used per treatment and each replicate contained five PDA plates.

In vivo antifungal assay. Maradol papaya fruit was collected at maturity index 4 (skin clearly orange in color with some light green areas; uniform weight, $900 \pm 200 \mathrm{~g}$; free of injuries and pesticides) from a commercial plantation located at Culiacan Sinaloa, Mexico.

Fruits were washed with $1 \%(\mathrm{v} / \mathrm{v})$ sodium hypochlorite, rinsed and air-dried at $25 \pm 2{ }^{\circ} \mathrm{C}$ for $1 \mathrm{~h}$, and then dipped for $5 \mathrm{~min}$ in a conidial suspension of $C$. gloeosporioides (1.5 $\times 10^{5}$ conidia/ ml) containing $0.5 \%(\mathrm{v} / \mathrm{v})$ Tween $80^{\circledR}$. The inoculated fruits were air-dried for $1 \mathrm{~h}$ again and randomly divided into 4 lots of 36 fruits each. One lot was untreated (control), other immersed in hot water $\left(48^{\circ} \mathrm{C}\right)$, the third one immersed in a solution containing $1 \%(\mathrm{w} / \mathrm{v})$ calcium chloride (Food grade, CCFO21-00 Fabpsa, Mexico) at room temperature, and the fourth lot was treated by immersion in water containing $1 \%(\mathrm{w} / \mathrm{v})$ calcium chloride at $48^{\circ} \mathrm{C}$. All immersions were done for $20 \mathrm{~min}$.

The treated fruits were individually packed in unsealed plastic bags and stored at $12{ }^{\circ} \mathrm{C}(90-95 \%$ relative humidity) for 20 days. Six fruits of each treatment were randomly removed every 4 days for physical and chemical analysis, and 36 fruits were used for each treatment during the entire storage period for anthracnose incidence and severity analysis. Three replicates per treatment were performed.

Disease incidence and severity. Fruit disease incidence based on the anthracnose symptoms was assessed every 2 days according to Ali et al. (2015) and applying the equa- tion:

$$
\begin{aligned}
& \text { Disease incidence }(\%) \\
& =\frac{\text { Numbe of infected fruits }}{\text { Total number of inoculated fruits }} \times 100
\end{aligned}
$$

Fruit disease severity was visually evaluated every 4 days and reported as percentage of fruit surface with anthracnose symptoms (Madani et al., 2016).

Measurement of fruit calcium. Pulp samples were dried at $60^{\circ} \mathrm{C}$ for $5 \mathrm{~h}$. Dried sample $(0.25 \mathrm{~g})$ was finely crushed and digested with $5 \mathrm{ml} \mathrm{H}_{2} \mathrm{SO}_{4}$ at $450^{\circ} \mathrm{C}$ for $7 \mathrm{~min}$. Sample was oxidized with $10 \mathrm{ml} \mathrm{H}_{2} \mathrm{O}_{2}$ at $450^{\circ} \mathrm{C}$ for 6 min and made up to $100 \mathrm{ml}$ with deionized water (Madani et al., 2016). Calcium content was determined with a Perkin Elmer 3110 atomic absorption spectrometer (PerkinElmer Inc., USA) and expressed as $\mathrm{mg} / 100 \mathrm{~g}$ fresh fruit. Measurements were done by triplicate.

Physicochemical quality of fruits. Weight loss was measured every 4 days according to Al-Eryani et al. (2008) and reported as percentage of weight loss. External fruit color $\left(\mathrm{L}^{*}, \mathrm{C}^{*}\right.$, and $\left.\mathrm{H}^{\circ}\right)$ at the equator region of opposing faces of each fruit was evaluated using a CR-200 colorimeter (Minolta Co. Ltd., Osaka, Japan) and twelve measurements per treatment were made avoiding fungal lesions according to Rashid et al. (2015). Firmness (reported in Newton, $\mathrm{N}$ ) of horizontally-cut fruit slices was measured using a Chatillon penetrometer (DFE 100; AMETEK Inc., Largo, Fla., USA) fitted with an $11 \mathrm{~mm}$ diameter cylindrical probe and a penetration depth of $5 \mathrm{~mm}$ and speed of $50 \mathrm{~mm} / \mathrm{min}$ (Ayón-Reyna et al., 2015). Total soluble solids (TSS) were measured with a handheld refractometer (Atago, Fisher Scientific, GA, USA) and results were expressed as ${ }^{\circ}$ Brix (Ali et al., 2015). Titratable acidity of the solution was determined as described by Ayón-Reyna et al. (2015) and reported as percentage of citric acid.

Statistical analysis. A completely randomized experimental design with three replicates was performed, considering treatment and storage time as factors. Statistical analysis of data was performed through analysis of variance using Statgraphics plus 5.1 (Statistical Graphics, Warrenton, VA, USA) and the means were compared using Fisher's least significant difference (LSD) test $(P \leq 0.05)$. The means with their corresponding standard deviation and letters indicating LSD at each time point were plotted using SigmaPlot 12.0 (SYSTAT Software Inc, San Jose, CA, USA). 


\section{Results}

In vitro antifungal assay. The treatment of $C$. gloeosporioides conidia with hot water alone or in combination with calcium inhibited the mycelial growth $(\mathrm{HW}=13.14 \%$; HW-Ca $=14.1 \%$ ), whereas calcium alone did not show any significant effect (Fig. 1A). All treatments significantly inhibited the conidial germination, although the combination HW-Ca showed the greatest effect (Fig. 1B). After 7 days of incubation, Petri dishes containing untreated and Ca treated C. gloeosporioides conidia reached the edge of the plate by first time (Fig. 1C).

In vivo antifungal assay. The incidence of anthracnose in papaya fruit was affected by the treatment applied and the time of storage $(P<0.05)$ (Fig. 2A). In this regard, the HW-Ca treatment protected the fruit. For all treatments, papaya fruit were free of symptoms up to four days of storage, but the symptoms appeared after 6, 8, 10 and 12 days in control, $\mathrm{Ca}, \mathrm{HW}$ and HW-Ca treated fruit, respectively (Fig. 2A). The $\mathrm{Ca}$ treatment increased the rate of anthrac- nose incidence, reaching the maximum value (100\%) after 12 days of storage; such value was obtained after 14 days in control and HW treatments and after 16 days in the combination HW-Ca.

Anthracnose severity on papaya fruit was dependent on the treatment and storage time $(P<0.001)$ (Fig. 2B), and $\mathrm{Ca}$ treated fruit was particularly more sensitive. After 8 days of storage, the affected surface area of $\mathrm{Ca}$ treated fruit $(25.8 \%)$ was significantly higher than that of control fruit (4\%). After 16 days of storage, fruit of all treatments were affected by anthracnose (100\% incidence), but the severity of this disease was lower in HW treated fruit, showing the lowest severity in the HW-Ca treatment (Fig. 2C). At the end of the storage period, control and $\mathrm{Ca}$ treated fruit showed the greatest damage, and for the HW treated fruits (HW and HW-Ca) was the lowest. Remarkably, the HWCa treatment provided the best fruit protection (Fig. 2B).

Fruit calcium. The highest calcium content was registered in the HW-Ca fruit, which showed a significant increase with the storage time $(P<0.05)($ Fig. 3A). Neither the $\mathrm{Ca}$ treatment nor the HW treatment increased significantly the
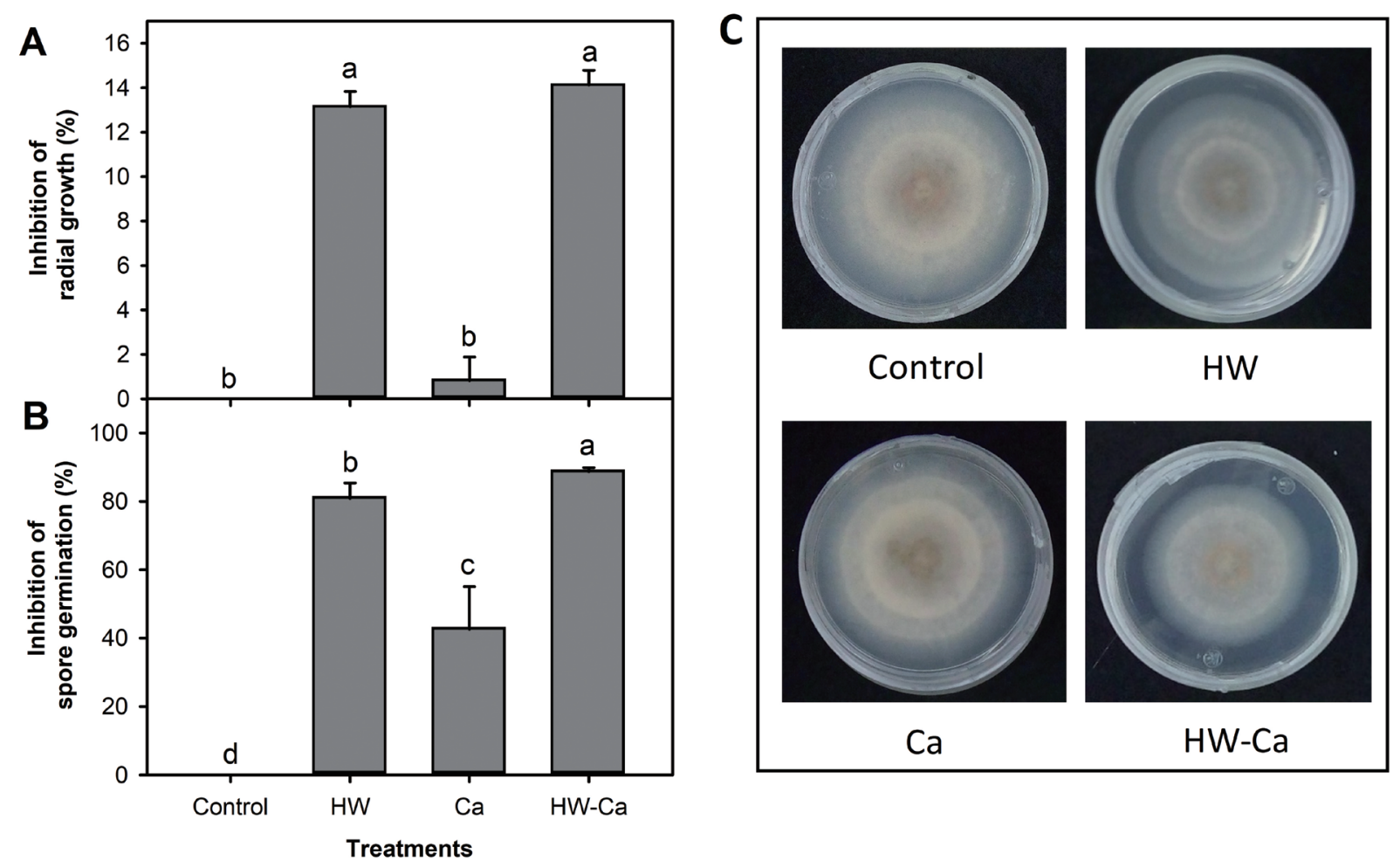

Fig. 1. In vitro radial growth (A) and spore germination (B) of Colletotrichum gloeosporioides conidia treated with hot water (HW), calcium chloride $(\mathrm{Ca})$, and a combination of hot water with calcium chloride (HW-Ca). Vertical bars represent the standard deviation of means for 3 replicates. Different letters indicate significant differences among treatments according to the Fisher's test $(P<0.05)$. $(C)$ Representative images of Petri dishes inoculated with Colletotrichum gloeosporioides conidia from each treatment showing mycelial growth after 7 days of incubation at $28^{\circ} \mathrm{C}$. 
fruit calcium content, suggesting a synergic effect for the combined treatment (HW-Ca).

Fruit physicochemical quality. Fruit of all treatments showed a gradual and significant increase in weight loss during the storage time $(P<0.001)$, but only the HW-Ca treated fruit showed a significantly lower weight loss at the end of storage $(P<0.05)$ (Fig. 3B).

The lightness $\left(\mathrm{L}^{*}\right)$ values of all treated papaya fruit remained constant during the first 12 days of storage, followed by a significant decrease until the end of the storage period $(P<0.001)$. This parameter was not significantly affected by the treatment $(P>0.05)$ (Fig. 4A). Considering the chroma $\left(\mathrm{C}^{*}\right)$ and hue angle $\left(\mathrm{H}^{*}\right)$ parameters, both the storage time and the applied treatment showed a significant effect $(P<0.001)$ (Fig. 4B, C). The $\mathrm{C}^{*}$ values of all treated papaya fruit increased with the storage time; at the end of the storage time and contrasting with the control fruit (the highest $C^{*}$ values), the lowest $C^{*}$ values were for the $\mathrm{HW}$ $\mathrm{Ca}$ treated fruit (Fig. 4B). On the other hand, the $\mathrm{H}^{*}$ values of all treated papaya decreased with the storage time; the skin color changed from slightly orange with green stripes to completely orange. At the end of the storage period, the HW-Ca treated fruit showed the highest $\mathrm{H}^{*}$ values, demonstrating a slower rate of color change (Fig. 4C). Thus, all reflectance color parameters agreed with the highest protective effect of the HW-Ca treatment (Fig. 4).

The firmness of papaya fruit decreases during normal ripening. Compared with the control, the fruit of all other treatments showed better retention of firmness $(P<0.001)$, but the best effect was observed in HW-Ca treated fruit (Fig. $5 \mathrm{~A})$.

The total soluble solids (TSS) content of fruit increases during normal ripening process; thus, a lower rate-in-rise
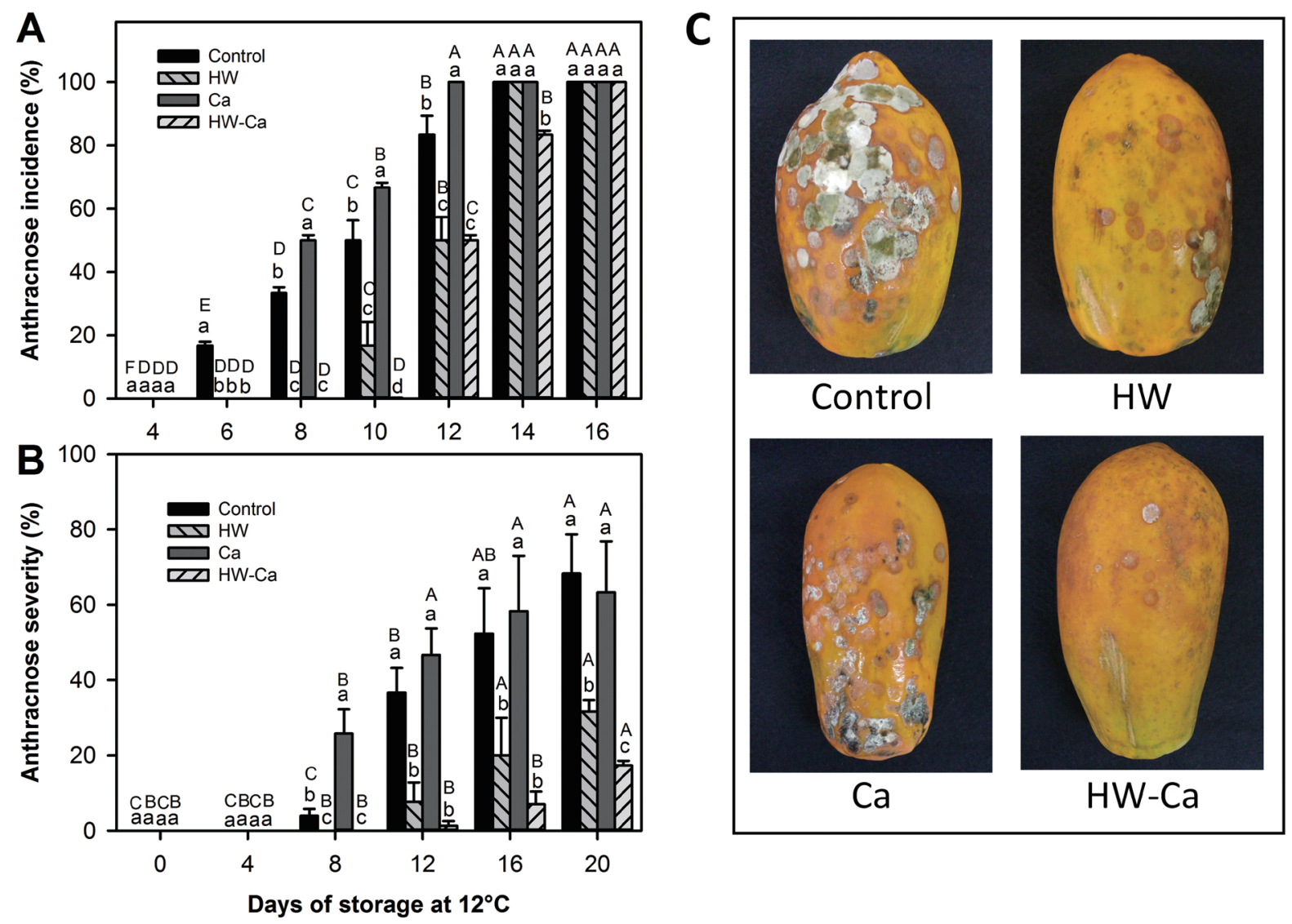

Fig. 2. Effect of hot water (HW), calcium chloride (Ca), and a combination of hot water with calcium chloride (HW-Ca) on incidence (A) and severity (B) of anthracnose disease in papaya inoculated with Colletotrichum gloeosporioides conidia and stored at $12^{\circ} \mathrm{C}$ for 20 days. Vertical bars represent the standard deviation of means for three replicates. For the same day, different lowercase letters indicate significant differences among treatments according to Fisher's test $(P<0.05)$. For the same treatment, different uppercase letters indicate significant differences among days of storage according to Fisher's test $(P<0.05)$. (C) Representative images of papaya fruit from each treatment showing anthracnose symptoms on the surface after 16 days of storage at $12^{\circ} \mathrm{C}$. 
indicates that ripening is being delayed. In general during storage time, the HW treatments (HW and HW-Ca) showed a protective effect characterized by lower TSS values and the HW-Ca treatment was the best by the end of the storage; in fact, the TSS values of the HW-Ca treated fruit remained constant during the storage time (Fig. 5B).

The titratable acidity (TA) of all treated papaya fruit decreased during the storage from $0.08 \%$ to $0.047 \%$ in the control and to $0.058 \%$ in HW-Ca treated fruit $(P<0.001)$; however, the treatments had no significant effect on TA $(P$ $>0.05)$ (Fig. 5C).

\section{Discussion}

Hot water treatments (HW and HW-Ca) showed good
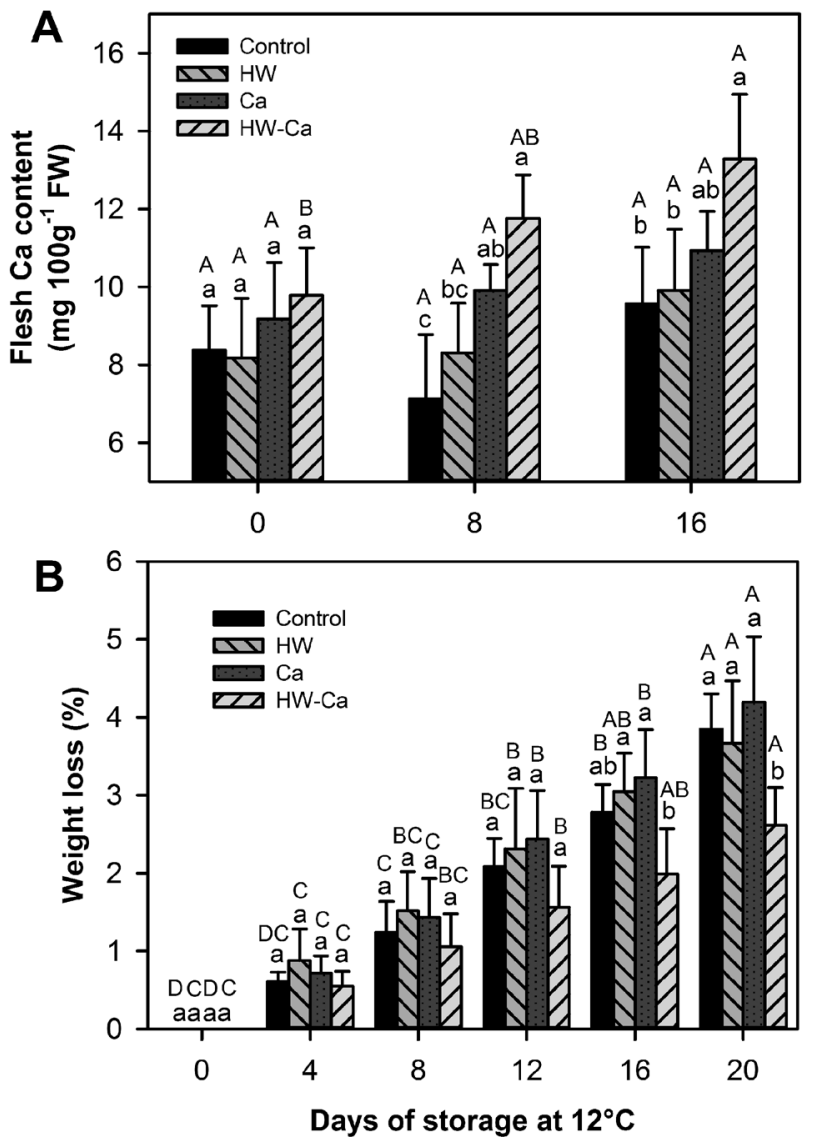

Fig. 3. Effect of hot water (HW), calcium chloride (Ca) and the combination of HW and $\mathrm{Ca}$ (HW-Ca) on calcium content (A) and weight loss (B) during the storage at $12{ }^{\circ} \mathrm{C}$ of Maradol papaya inoculated with Colletotrichum gloeosporioides. Values represent the mean \pm standard deviation of three independent replicates. For the same day, different lowercase letters indicate significant differences among the treatments $(P<0.05)$. For the same treatment, different uppercase letters indicate significant differences among days of storage according to Fisher's test $(P<0.05)$. antifungal activity against $C$. gloeosporioides in both in vitro and in vivo tests. In vitro, $\mathrm{HW}$ and $\mathrm{HW}-\mathrm{Ca}$ treatments inhibited both the mycelial growth and the conidial germination of $C$. gloeosporioides, whereas Ca treatment only decreased the conidial germination (Fig. 1A, B).

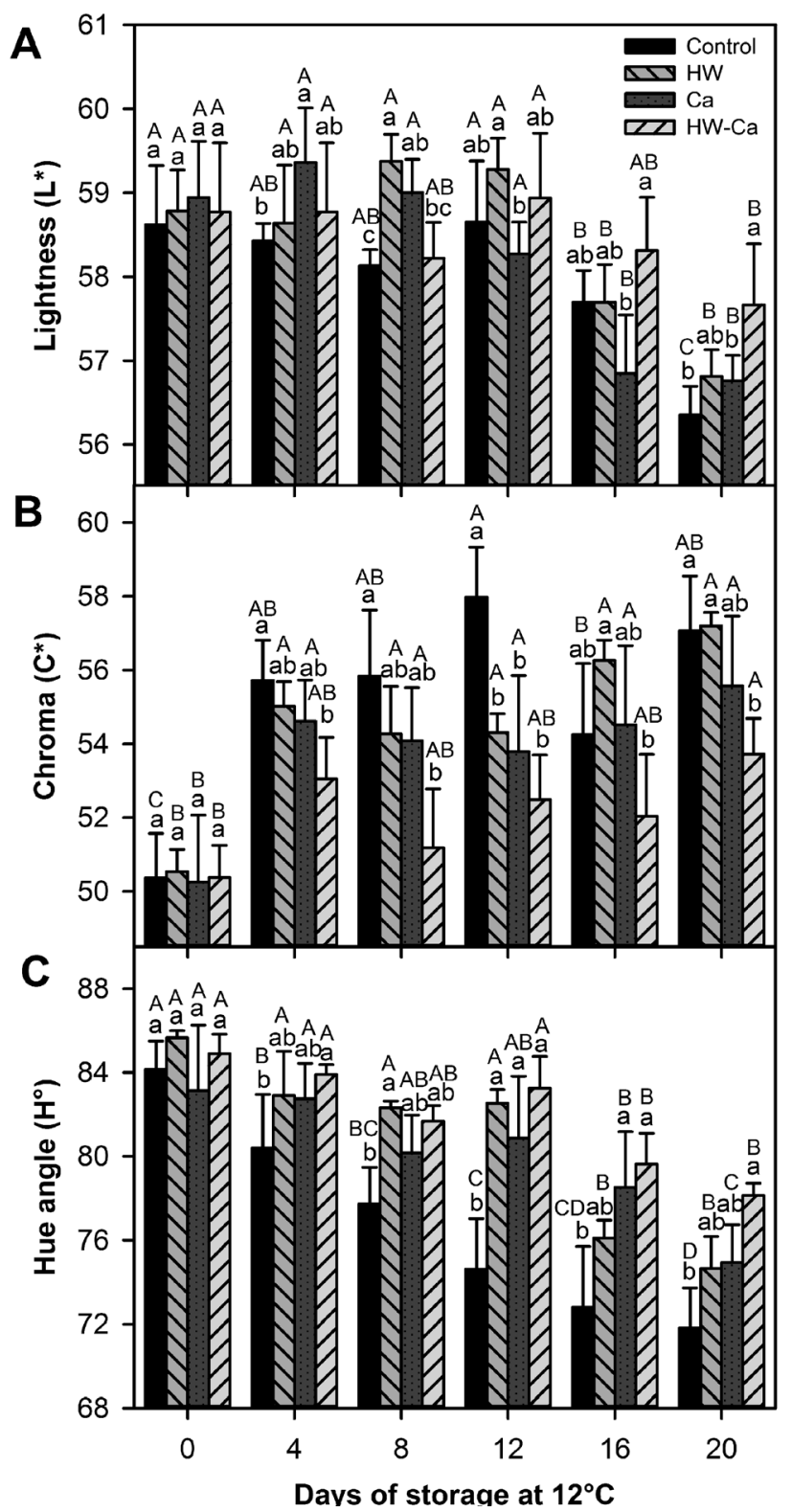

Fig. 4. Effect of hot water (HW), calcium chloride (Ca) and their combination (HW-Ca) on lightness (A), chroma (B) and hue angle $(\mathrm{C})$ during the storage at $12^{\circ} \mathrm{C}$ of Maradol papaya inoculated with Colletotrichum gloeosporioides. Vertical bars on columns represent the standard deviation of the means for three replicates. For the same day, different lowercase letters indicate significant differences among the treatments $(P<0.05)$. For the same treatment, different uppercase letters indicate significant differences among days of storage according to Fisher's test $(P<0.05)$. 
These findings agree with the those previously reported by Madani et al. (2014); they observed that treating $C$. gloeosporioides with $1 \% \mathrm{CaCl}_{2}$ decreased spore germination but stimulated the mycelial growth, indicating that the pathogen conidia was more sensitive to calcium than mycelium. According to Al-Eryani-Raqeeb et al. (2009), fungal cells exposed to high calcium concentration increase their calcium level in the cytosol, which could alter the osmotic balance and be toxic for the fungus. Warwar and Dickman (1996) evaluated the effect of internal and external calcium on Colletotrichum trifolii using EGTA (ethylene-bis (oxy-ethylenenitrolo) tetraacetic acid); calcium chelation induced the germination of $C$. trifolii spores; however, the formation of appressoria was inhibited. They also found that adding $\mathrm{Ca}^{+2}$ restored the ability of spores to differentiate to mature appressoria, indicating that calcium is required for differentiation and colony growth of C. trifolii. In this sense, Griffin (1966) reported that calcium at optimum concentrations was required for the formation of spores and sporangia, whereas high concentrations reduced their differentiation. On the other hand, the reduction of spore germination and mycelial growth by the hot water treatment could be mainly due to a direct effect of the high temperature on the fungus as reported by Conway et al. (1999), who observed that heat treatment reduced the survival of Penicillium expansum conidia.

In vivo, hot water treatments (HW and HW-Ca) of papaya infected with $C$. gloeosporioides reduced the incidence and severity of anthracnose, obtaining better results with the combined HW-Ca treatment, which delayed the appearance of symptoms up to 6 days and reduced the disease severity (Fig. 2). Considering the inhibitory effect of $\mathrm{Ca}$ treatment on conidial germination (Fig. 1B), the increased incidence and severity of papaya anthracnose observed for this treatment was unexpected (Fig. 2A, B). This could be partially explained because $\mathrm{Ca}$ treatment did not significantly increase the pulp calcium content, but the HW-Ca $\operatorname{did}$ (Fig. 3A). In addition, the fruit could protect the conidia against heat and calcium, while in the in vitro test the conidia were directly exposed to these treatments. These results agree with those of Sharma et al. (2013) who reported higher calcium content and lower incidence of Penicillium expansum and Botrytis cinerea in apple fruit treated with the combination HW-Ca than in fruit treated with HW or $\mathrm{Ca}$ alone.

The reduction of anthracnose symptoms in hot water treated fruit could be due to a direct effect on C. gloeosporioides; high temperatures could affect enzymes and other proteins of the fungus and inhibit its growth (Martins and Blum, 2014). The HW treatment reduced the incidence and severity of anthracnose in papaya fruits (Li et al., 2013; Rashid et al., 2015), and the size of the lesions caused by $C$. gloesoporioides in guava (Ferraz et al., 2013) and by Monilinia laxa in peach (Spadoni et al., 2014). On the other hand,

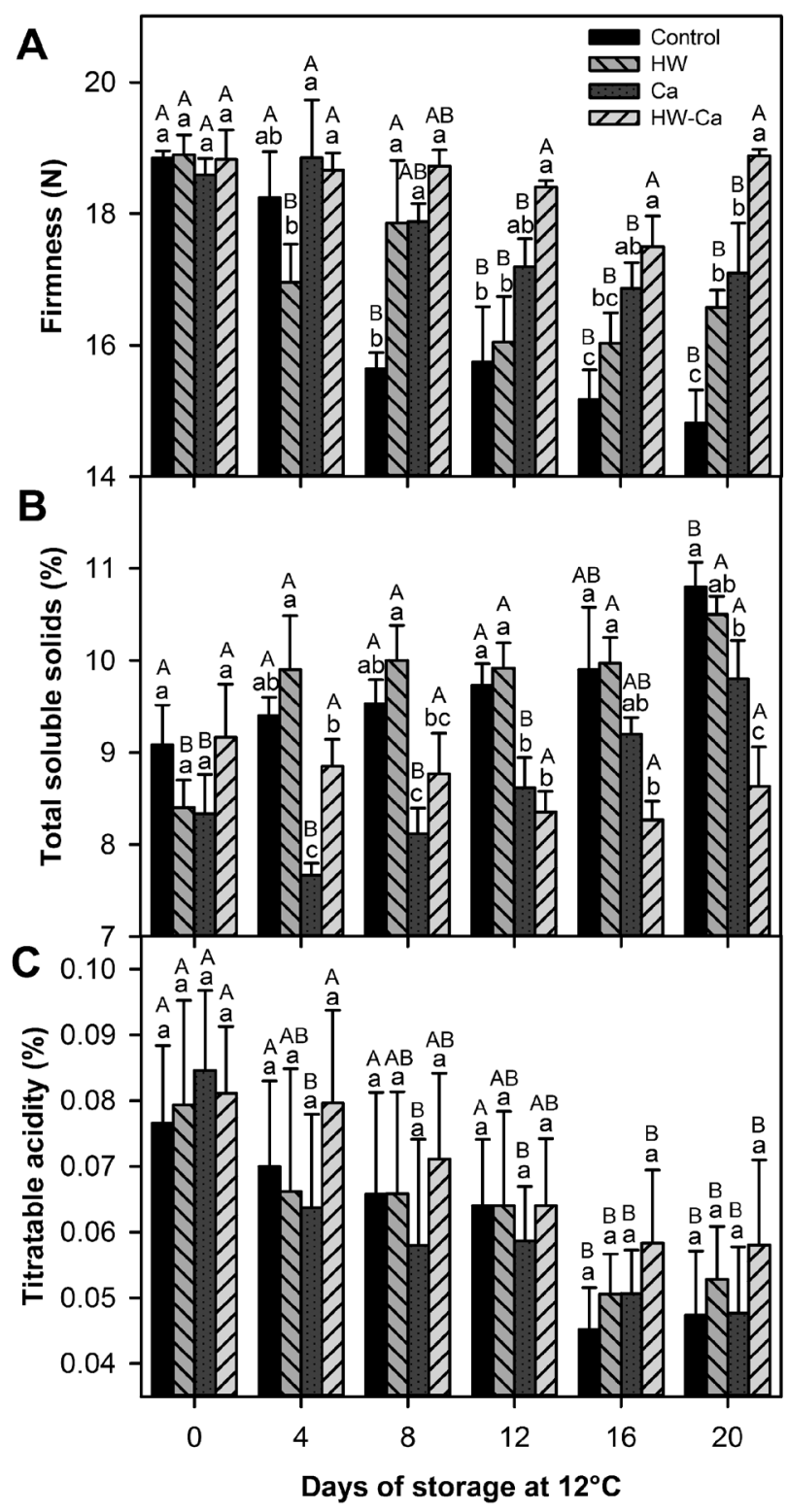

Fig. 5. Effect of hot water (HW), calcium (Ca), and a combination of $\mathrm{HW}$ and $\mathrm{Ca}$ (HW-Ca) on firmness (A), total soluble solids (B) and titratable acidity (C) of papaya inoculated with Colletotrichum gloeosporioides after 20 days of storage at $12^{\circ} \mathrm{C}$. Vertical bars on columns represent the standard deviation of the means for three replicates. For the same day, different lowercase letters indicate significant differences among the treatments $(P<0.05)$. For the same treatment, different uppercase letters indicate significant differences among days of storage according to Fisher's test $(P<$ $0.05)$. 
several studies have found that calcium chloride reduces the incidence and severity of fungal anthracnose in papaya (Al-Eryani-Raqeeb et al., 2009; Madani et al., 2016), apple (Zhao and Wang, 2015), guava (Cruz et al., 2015), and dragon fruits (Awang et al., 2011; Ghani et al., 2011). The Ca treatment of the present study did not reduce papaya anthracnose, perhaps because the calcium concentration or the time used was not enough to allow an internal concentration in the fruit that prevents fungal growth. Previous studies have shown similar results; a $2 \%(\mathrm{w} / \mathrm{v})$ calcium chloride treatment did not protect banana clusters against the crown rot caused by Colletotrichum musae (Bastiaanse et al., 2010), whereas the incidence and severity of papaya anthracnose was only reduced at calcium chloride concentrations higher than 1\% (Madani et al., 2016).

It has been reported that the mechanism by which calcium reduces the fruit decay is related to formation of calcium pectate, which stabilizes the cell wall (Sharma et al., 2013), and the severity of the disease decreases at higher calcium concentrations (Awang et al., 2011). Although calcium treatment of papaya fruit delayed the onset of anthracnose symptoms in papaya fruit, 8 days versus 6 days for the control fruit, after 8 days of storage, the anthracnose incidence and severity of $\mathrm{Ca}$ treated fruit were equal or higher than that of the control fruit. Thus, calcium could be affecting the stage of spore germination, and the onset of anthracnose is delayed. After spore germination, mycelial growth is not affected, and the damage of calcium treated fruit is similar to that of control fruit.

Combining hot water and calcium chloride resulted in a more effective protection of papaya against $C$. gloesporioides anthracnose than either treatment alone. Heat treatment of the fruit increases the cell permeability and the calcium penetration is facilitated (Silveira et al., 2011). This phenomenon has been demonstrated in papaya (Madani et al., 2014), dragon fruit (Awang et al., 2011), apple (Hemmaty et al., 2007; Sharma et al., 2013), melon (Aguayo et al., 2008), and other fruits. In apple, Sharma et al. (2013) observed that untreated fruit exhibited higher decay area caused by Penicillium expansum and Botrytis cinerea than those treated with calcium, hot water or their combination; hot water treatment was better than calcium treatment, and an additive effect resulted of the application of the combined treatment. Aguayo et al. (2015) reported a reduction in growth of yeasts and fungi in apple slices treated with the combination $\mathrm{HW}-\mathrm{Ca}$, while application of $\mathrm{Ca}$ alone was not effective.

The fungal pathogen must first attack the fruit skin, where fungus secretes cell wall degrading enzymes leading to loss of fruit firmness and favoring the fungal infection
(Awang et al., 2011); however, heat treatment of infected fruit can hinder fungal germination and growth by exerting either lethal or sublethal effects (Ayón-Reyna et al., 2015). Remarkably, heat activates fruit pectin methylesterase, which demethylates pectin and the free anionic carboxyl groups form calcium pectates in the presence of calcium ions. These pectates strengthen the cell walls, reducing the fruit susceptibility to fungal attack because the substrates are less available to fungal hydrolases that macerate the tissue and the fruit quality remains for longer time (Aguayo et al., 2008; Awang et al., 2011; Ayón-Reyna et al., 2015). Additionally, our previous report shows that hot water and calcium chloride combined treatment melts the epicuticular wax, forming a physical barrier that reduces the mycelial growth on papaya fruit (Ayón-Reyna et al., 2017).

Data suggested that HW-Ca delayed the ripening process; it was the only treatment that retained significantly the quality parameters of papaya; i.e., lower weight loss (Fig. 3B) and total soluble solids, higher firmness and titratable acidity (Fig. 5), as well as better color retention (Fig. 4). Weight loss, firmness and external color are some of the most important quality parameters used by the consumers to decide if the fruit is suitable for consumption. Ripening of most climacteric fruit is characterized by softening of the flesh, enhanced color development, gas exchange, and increased sugar/acid ratio. Exposing fruit to high temperatures retards some of these processes while enhancing others (Li et al., 2013). In our case, HW-Ca was effective to retard the changes of the main quality parameters, thus maintaining the fruit quality for a longer period during storage and shelf life. Hot water combined with calcium have been shown to improve the quality and shelf life of other fruit crops such as melon (Aguayo et al., 2008), and apple (Aguayo et al., 2015; Hemmaty et al., 2007).

The immersion of papaya in hot water containing calcium chloride may be a useful integrated strategy to control $C$. gloeosporioides anthracnose, to delay the ripening process and to improve the quality and shelf life of the fruit. Both hot water and calcium chloride treatments are innocuous, and the combined treatment represents a better option than the use of chemical fungicides due to safety concerns.

\section{References}

Ademe, A., Ayalew, A. and Woldetsadik, K. 2013. Evaluation of antifungal activity of plant extracts against papaya anthracnose (Colletotrichum gloeosporioides). J. Plant Pathol. Microb. 4:10.

Aguayo, E., Escalona, V. H. and Artés, F. 2008. Effect of hot water treatment and various calcium salts on quality of fresh-cut 
‘Amarillo' melon. Postharvest Biol. Technol. 47:397-406.

Aguayo, E., Requejo-Jackman, C., Stanley, R. and Woolf, A. 2015. Hot water treatment in combination with calcium ascorbate dips increases bioactive compounds and helps to maintain fresh-cut apple quality. Postharvest Biol. Technol. 110:158-165.

Ajay Kumar, G. 2014. Colletotrichum gloeosporioides: biology, pathogenicity and management in India. J. Plant Physiol. Pathol. 2:2.

Al-Eryani, A. R., Mahmud, T. M. M., Syed, S. R. and Mohamed, A. R. 2008. Effects of calcium infiltration and chitosan coating on storage life and quality characteristics during storage of papaya (Carica papaya L.). Int. J. Agric. Res. 3:296-306.

Al-Eryani-Raqeeb, A., Mahmud, T. M. M., Syed Omar, S. R., Mohamed Zaki, A. R. and Al-Eryani, A. R. 2009. Effects of calcium and chitosan treatments on controlling anthracnose and postharvest quality of papaya (Carica papaya L.). Int. J. Agric. Res. 4:53-68.

Ali, A., Wee Pheng, T. and Mustafa, M. A. 2015. Application of lemongrass oil in vapour phase for the effective control of anthracnose of 'Sekaki' papaya. J. Appl. Microbiol. 118:14561464.

Awang, Y., Azlan Abdul Ghani, M., Sijam, K. and Mohamad, R. 2011. Effect of calcium chloride on anthracnose disease and postharvest quality of red-flesh dragon fruit (Hylocereus polyrhizus). Afr. J. Microbiol. Res. 5:5250-5259.

Ayón-Reyna, L. E., Tamayo-Limón, R., Cárdenas-Torres, F., López-López, M. E., López-Angulo, G., López-Moreno, H. S., López-Cervántes, J., López-Valenzuela, J. A. and VegaGarcía, M. O. 2015. Effectiveness of hydrothermal-calcium chloride treatment and chitosan on quality retention and microbial growth during storage of fresh-cut papaya. J. Food Sci. 80:C594-C601.

Ayón-Reyna, L. E., González-Robles, A., Rendón-Maldonado, J. G., Báez-Flores, M. E., López-López, M. E. and Vega-García, M. O. 2017. Application of a hydrothermal-calcium chloride treatment to inhibit postharvest anthracnose development in papaya. Postharvest Biol. Technol. 124:85-90.

Bastiaanse, H., De Bellaire, L. D. L., Lassois, L., Misson, C. and Jijakli, M. H. 2010. Integrated control of crown rot of banana with Candida oleophila strain O, calcium chloride and modified atmosphere packaging. Biol. Control 53:100-107.

Conway, W. S., Janisiewicz, W. J., Klein, J. D. and Sams, C. E. 1999. Strategy for combining heat treatment, calcium infiltration, and biological control to reduce postharvest decay of 'Gala' apples. HortScience 34:700-704.

Cruz, A. F., Medeiros, N. L., Benedet, G. L., Araújo, M. B., Uesugi, C. H., Ferreira, M. A. D., Peixoto, J. R. and Blum, L. E. B. 2015. Control of post-harvest anthracnose infection in guava (Psidium guajava) fruits with phosphites, calcium chloride, acetyl salicylic acid, hot water, and 1-MCP. Hortic. Environ. Biotechnol. 56:330-340.

Dessalegn, Y., Ayalew, A. and Woldetsadik, K. 2013. Integrating plant defense inducing chemical, inorganic salt and hot water treatments for the management of postharvest mango anthracnose. Postharvest Biol. Technol. 85:83-88.

Ferraz, D. M. M., Blum, L. E. B., Cruz, A. F., Uesugi, C. H. and Peixoto, J. R. 2013. Reduction of guava anthracnose (Colletotrichum gloeosporioides) by hot water treatments of fruits from organic or conventional system of production. Int. J. Postharvest Technol. Innov. 3:272-284.

Ghani, M. A. A., Awang, Y. and Sijam, K. 2011. Disease occurrence and fruit quality of pre-harvest calcium treated red flesh dragon fruit (Hylocereus polyrhizus). Afr. J. Biotechnol. 10:1550-1558.

Griffin, D. H. 1966. Effect of electrolytes on differentiation in Achlya sp. Plant Physiol. 41:1254-1256.

Hemmaty, S., Moallemi, N., Naseri, L. 2007. Effect of UV-C radiation and hot water on the calcium content and postharvest quality of apples. Span. J. Agric. Res. 5:559-568.

Kechinski, C. P., Montero, C. R. S., Noreña, C. P. Z., Tessaro, I. C., Marczak, L. D. F. and Bender, R. J. 2012. Effects of ozone in combination with hydrothermal treatment and wax on physical and chemical properties of papayas. Ozone Sci. Eng. 34:57-63.

Li, X., Zhu, X., Zhao, N., Fu, D., Li, J., Chen, W. and Chen, W. 2013. Effects of hot water treatment on anthracnose disease in papaya fruit and its possible mechanism. Postharvest Biol. Technol. 86:437-446.

Machado, L. P., Matsumoto, S. T., Jamal, C. M., da Silva, M. B., da Cruz Centeno, D., Neto, P. C., de Carvalho, L. R. and Yokoya, N. S. 2014. Chemical analysis and toxicity of seaweed extracts with inhibitory activity against tropical fruit anthracnose fungi. J. Sci. Food Agric. 94:1739-1744.

Madani, B., Mohamed, M. T. M., Biggs, A. R., Kadir, J., Awang, Y., Tayebimeigooni, A. and Shojaei, T. R. 2014. Effect of preharvest calcium chloride applications on fruit calcium level and post-harvest anthracnose disease of papaya. Crop Prot. 55:55-60.

Madani, B., Mirshekari, A. and Yahia, E. 2016. Effect of calcium chloride treatments on calcium content, anthracnose severity and antioxidant activity in papaya fruit during ambient storage. J. Sci. Food Agric. 96:2963-2968.

Martins, D. M. S. and Blum, L. E. B. 2014. Reduction of anthracnose and post-harvest dry rot in papaya by hydrothermia. Rev. Caatinga 27:98-105.

National Research Council. 1996. Carcinogens and anticarcinogens in the human diet: a comparison of naturally occurring and synthetic substances. National Academies Press, Washington. URL https://www.ncbi.nlm.nih.gov/books/ NBK232630/.

Ong, M. K., Kazi, F. K., Forney, C. F. and Ali, A. 2013. Effect of gaseous ozone on papaya anthracnose. Food Bioproc. Technol. 6:2996-3005.

Pérez-Carrillo, E. and Yahia, E. 2004. Effect of postharvest hot air and fungicide treatments on the quality of 'Maradol' papaya (Carica papaya L.). J. Food Qual. 27:127-139.

Perumal, A. B., Sellamuthu, P. S., Nambiar, R. B. and Sadiku, E. R. 
2016. Antifungal activity of five different essential oils in vapour phase for the control of Colletotrichum gloeosporioides and Lasiodiplodia theobromae in vitro and on mango. Int. J. Food Sci. Technol. 51:411-418.

Rashid, M. H. A., Grout, B. W. W., Continella, A. and Mahmud, T. M. M. 2015. Low-dose gamma irradiation following hot water immersion of papaya (Carica papaya linn.) fruits provides additional control of postharvest fungal infection to extend shelf life. Radiat. Phys. Chem. 110:77-81.

Sharma, R. R., Singh, D. and Pal, R. K. 2013. Synergistic influence of pre-harvest calcium sprays and postharvest hot water treatment on fruit firmness, decay, bitter pit incidence and postharvest quality of royal delicious apples (Malus $x$ domestica Borkh). Am. J. Plant Sci. 4:153-159.
Silveira, A. C., Aguayo, E., Chisari, M. and Artés, F. 2011. Calcium salts and heat treatment for quality retention of fresh-cut 'Galia' melon. Postharvest Biol. Technol. 62:77-84.

Spadoni, A., Guidarelli, M., Sanzani, S. M., Ippolito, A. and Mari, M. 2014. Influence of hot water treatment on brown rot of peach and rapid fruit response to heat stress. Postharvest Biol. Technol. 94:66-73.

Warwar, V. and Dickman, M. B. 1996. Effects of calcium and calmodulin on spore germination and appressorium development in Colletotrichum trifolii. Appl. Environ. Microbiol. 62:74-79.

Zhao, Y. and Wang, C. 2015. Effect of calcium chloride in combination with salicylic acid on post-harvest freshness of apples. Food Sci. Biotechnol. 24:1139-1146. 